\title{
MENGKAJI ALTERNATIF PENGELOLAAN LIMBAH PADAT KOTA PALU BERDASARKAN BIAYA PENGELOLAAN OPTIMAL
}

\author{
D. A. Pratamasyari1)* \\ 1IAIN PALU \\ 1 dedearseyani@gmail.com
}

\begin{abstract}
Waste is one of the source environmental problem point problem that need to attention. Waste problem becomes complex to be solved because related to the waste management. In this research the waste management of Palu city will be considered in 2 cases. First case is convensional waste management of Palu city. Second case is a modern management alternative reused the waste to a valuable product. The unmanaged waste fraction parameter to the cost management is also to be consired. to the amount for cost of manage this waste also researched here. Research result shows that the waste management of Palu city can be derived into such optimal, with the models of mathematic is to minimize $\mathrm{F}_{1}+\mathrm{F}_{2}-B$ which to have 11 constraint. The riil cost for manage Palu city Rp.8.050.330.000 can be decreased to Rp.5.800.788.000. That cost can be decreased by minimizing the amount of delivered direct waste from the source to the landfill.
\end{abstract}

\section{Keywords : Cost Of Management Waste, Mathematical Models, Product, Waste Management Alternative, Optimal}

\section{ABSTRAK}

Sampah merupakan salah satu sumber masalah lingkungan yang perlu mendapat perhatian. Permasalahan sampah semakin kompleks untuk diselesaikan karena berkaitan erat dengan pengolahannya. Dalam penelitian iniPengelolaan sampah di Kota palu dikaji dalam 2 kasus. Kasus pertama merupakan pengelolaan sampah riil di Kota Palu yang dikelola secara konvensional. Kasus kedua merupakan alternatif pengelolaan sampah moderen yang dikelola dengan terlebih dahulu mengubah sampah menjadi produk yang memiliki nilai jual. Peran parameter fraksi sampah yang tidak tertangani terhadap besarnya biaya pengelolaan sampah dikaji pula. Hasil penelitian menunjukkan masalah pengelolaan sampah kota Palu dapat dikaji melalui model matematika untuk mendapatkan biaya pengelolaan yang optimal, dengan model matematika meminimumkan $F_{1}+F_{2}-B$ yang mempunyai 11 fungsi kendala. Pengelolaan sampah riil kota Palu sebesar Rp.8.050.330.000 dapat ditekan menjadi Rp.5.800.788.000. Nilai tersebut masih dapat ditekan dengan meminimumkan banyaknya sampah dari sumber yang langsung diangkut ke landfill.

Kata Kunci : Alternatif Pengelolaan Sampah, Program Linier, Biaya Pengelolaan Sampah, Produk, Optimal Mathematics Subject Classification (MSC): 05 C78 (Ini Contoh MSC Untuk Pelabelan Graf) 


\section{PENDAHULUAN}

Sampah merupakan salah satu sumber masalah lingkungan yang perlu mendapat perhatian. Permasalahan sampah semakin kompleks untuk diselesaikan karena berkaitan erat dengan pengolahannya, kuantitasnya, jenisnya, dll. Dewasa ini pengelolaan sampah bahkan semakin rumit dikarenakan variasi jenis sampah semakin beragam, sumber dana bagi penanganannya terbatas dan dampak perkembangan ekonomi yang mengakibatkan aktivitas - aktivitas sumber potensial adanya sampah menjadi semakin tinggi.

Tingginya volume sampah dapat menimbulkan pencemaran apabila daya asimilasi alam tidak mampu lagi mendukungnya. Bila kondisi ini terjadi permasalahannya berkaitan dengan kesehatan masyarakat karena dari sampah tersebut dapat hidup berbagai organisme penyebab penyakit baik secara langsung maupun tidak langsung melalui perantara vektor.

Penyakit-penyakit tersebut antara lain Typhus Abdominalis, diare, Dengue Haemorhagic fever (Mukono, 1999). Akibat lain yang ditimbulkan oleh sampah adalah munculnya beberapa masalah lingkungan, antara lain penyumbatan saluran drainase yang mengakibatkan banjir dan genangan air pada beberapa lokasi, tempat berkembang biaknya lalat, nyamuk dan kecoa (Dinas Kebersihan Kota Palu, 2004).

Selain dapat menyebabkan penyakit, dari segi estetika sampah akan menjadi hal terburuk yang merusak pemandangan serta menimbulkan bau tidak sedap. Hal ini dapat menurunkan tolak ukur identitas kota dalam segala aspek. Oleh karena itu satu tantangan yang dihadapi oleh setiap pengelola perkotaan adalah pengelolaan sampah secara optimal. Berdasarkan data BPS tahun 2002, penanganan sampah dari 384 kota yang menghasilkan sampah sebesar 80.235,87 ton setiap hari, 4,2\% diangkut ke dan dibuang ke Tempat Pembuangan Akhir, dibakar sebesar 37,6\%, dibuang ke sungai $4,9 \%$ dan tidak tertangani sebesar $53,3 \%$ (Arianto Wibowo). Data tersebut memperlihatkan pengelolaan sampah yang tidak optimal mengingat besarnya persentasi sampah yang tidak tertangani.

Berdasarkan data Dinas Kebersihan Kota Palu, jumlah sampah yang dihasilkan Kota

Palu sebanyak $863 \mathrm{~m}^{3}$ per hari dan yang terangkut hanya sekitar 840 lebih $\mathrm{m}^{3}$ per hari (Dinas Kebersihan Kota Palu, 2004). Di jumpai pula sampah yang menumpuk di lahan terbuka dan tidak terangkut, mengingat sampah yang terangkut hanyalah sampah yang berada di sekitar jalan poros, sedangkan sampah yang berasal dari areal pemukiman yang tidak dapat dilalui oleh mobil angkutan tidak terangkut.

Penelitian ini mengkaji alternatif pengelolaan sampah di kota palu yang memandang sampah sebagai sumber daya yang mempunyai nilai. Dalam hal ini, sampah akan dikonversi menjadi bahan bakar energi listrik, kompos (bahan organik stabil) atau didaur ulang untuk digunakan kembali. Pengelolaan sampah yang demikian, memerlukan perencanaan yang matang agar pelaksanaan dapat 
berlangsung secara optimal. Perencanaan dibuat dalam bentuk model program linier dengan cara mendefinisikan semua aliran sampah yang harus dikirim dari tempat pembuangan sementara ke instansi pengolahan energi, kompos, daur ulang dan tempat pembuangan sampah akhir. Semua aliran diukur berdasarkan jumlah (berat atau volume), jenis dan lokasi tempat pembuangan sampah.

Dalam penelitian ini, pengelolaan sampah akan ditinjau berdasarkan biaya pengelolaan yang optimal, yaitu mencari biaya yang minimum. Menurut Susanta B (1994), hal ini dikenal dengan optimasi. Aliran sampah yang dimodelkan dalam bentuk program linier berkaitan dengan pengalokasian sumber daya yang langkah atau terbatas untuk mencapai tujuan tunggal seperti memaksimumkan keuntungan atau meminimumkan biaya (Siringoringo.2005). Profitabilitas dari sebuah kegiatan dapat diukur dalam bentuk penggunaan sumber daya dan kontribusinya (biaya) pada fungsi tujuan (Hamdi A Taha. 1996). Dalam penelitian ini fungsi tujuan mencerminkan total biaya pengelolaan sampah. Biaya tersebut meliputi biaya investasi dan manajemen masing-masing jenis pengolahan sampah, biaya pengangkutan sampah, biaya pembelian kendaraan pengangkut sampah dan produk olahan. Fungsi obyektif lain yang dibangun, mencerminkan keuntungan yang diperoleh dari penjualan produk olahan. Pengelolaan optimal akan dicapai bila selisih kedua fungsi tujuan tersebut adalah minimal.

\section{METODE PENELITIAN}

\subsection{Lokasi Penelitian}

Lokasi tempat pengambilan data bertempat di Dinas Kebersihan Kota Palu yang terletak di jalan Kakatua Palu Sulawesi Tengah. Sedangkan bentuk kegiatan penelitian dilakukan di laboratorium Terapan Jurusan Matematika Fakultas MIPA Universitas Tadulako

\subsection{Alat dan Bahan}

Adapun alat dan bahan yang digunakan dalam penelitian ini adalah Personal Komputer (PC) dengan Intel ${ }^{\circledR}$ Core $^{\mathrm{TM}}$ 13-2330 M 2 GB DDR3 Memory.

\subsection{Variable Penelitian}

Variabel yang akan diteliti adalah banyaknya truk pengangkut sampah $\left(x_{i}\right), \mathrm{i}=1 . \mathrm{h}$, truk pengangkut sisa olahan $\left(y_{j}\right), \mathrm{j}=1 . . \mathrm{k}$, banyaknya truk pengganti yang digunakan $\left(n_{s}\right), \mathrm{s}$

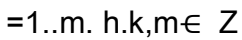

\subsection{Jenis dan Sumber Data}

Jenis data yang digunakan dalam penelitian ini berupa data kuantitatif yang diperoleh dari tempat penelitian yaitu Dinas Kebersihan Kota Palu yang jenis maupun biaya dari masing-masing variabel yaitu Kapasitas truk $(\mu)$, banyaknya perjalanan truk per hari $(\alpha)$, biaya transportasi sampah (a), biaya memindahkan truk pengganti (c), pendapatan per unit sampah (d), biaya pembelian truk baru (f), jumlah limbah pada sumber $\left(\mathrm{d}_{\mathrm{i}}\right)$, sampah yang tidak 
tertangani $(\rho)$, biaya menangani per ton sampah $\left(z_{i}\right)$, biaya untuk membeli truk baru $(e)$, dan peluang sebuah truk rusak dalam sehari $(P)$. Sedangkan sumber data yang digunakan dalam penelitian ini adalah data sekunder.

\subsection{Teknik Analisa Data}

Adapun teknik penganalisaan data yang digunakan oleh peneliti setelah memperoleh data-data yang dibutuhkan yaitu dengan menggunakan program linier.

\section{HASIL DAN PEMBAHASAN}

\subsection{Hasil}

Pengelolaan sampah di Kota Palu akan dikaji dalam 2 kasus, kasus pertama merupakan pengelolaan sampah riil di Kota Palu. Dalam hal ini sampah diangkut dari sumbernya (yaitu TPS) langsung menuju landfill. Kasus kedua merupakan alternatif pengelolaan sampah modern yang dikelola dengan terlebih diubah menjadi produk yang punya nilai jual. Selain data-data tersebut diperlukan pula data-data mengenai pendapatan dan kapasitas pada insinerator, RDF, kompos, dan daur ulang yang disortir wawancara dengan pegawai Dinas Kebersihan. Dengan hasil wawancara tesebut dimisalkan bahwa hasil pendapatan dan kapasitas ditunjukkan pada Tabel 1.

Tabel 1 : Hasil Wawancara Dengan Pegawai Dinas Kebersihan

\begin{tabular}{|c|l|l|}
\hline No & \multicolumn{1}{|c|}{ Data } & \multicolumn{1}{|c|}{ Banyaknya/ Biaya } \\
\hline 1 & Banyaknya Perjalanan Dari Tempat & \multicolumn{1}{|c|}{3 Ret } \\
2 & Pengolahan Sampah Ke Landfill 3000 \\
3 & Biaya Transportasi dari tempat pengolahan sampah ke & Rp. 160.000 \\
& landfill & Rp. 150.000 \\
4 & Pendapatan Per unit sampah pada Insinerator & Rp. 75.000 \\
4 & Pendapatan Per unit sampah pada RDF & Rp. 50.000 \\
6 & Pendapatan Per unit sampah pada Pengomposan & 1000,25 Kubik \\
7 & Pendapatan Per unit sampah pada Daur ulang & 1000,25 Kubik \\
8 & Kapasitas Pada Mesin Insinerator & 1000 kubik \\
9 & Kapasitas Pada Mesin RDF & $1000 \mathrm{ik}$ \\
10 & Kapasitas Pembuatan Kompos & \\
11 & Kapasitas Daur Ulang & \\
\hline
\end{tabular}

Alternatif pengelolaan sampah kota palu jika ditambahkan insinerator, RDF, Pengomposan, dan daur ulang. 


\subsubsection{Skema Pengelolaan Sampah}

Jika kota Palu memiliki insenerator, RDF, pengomposan, dan pusat daur ulang dari sampah maka skema pengelolaannya digambarkan sebagai berikut :

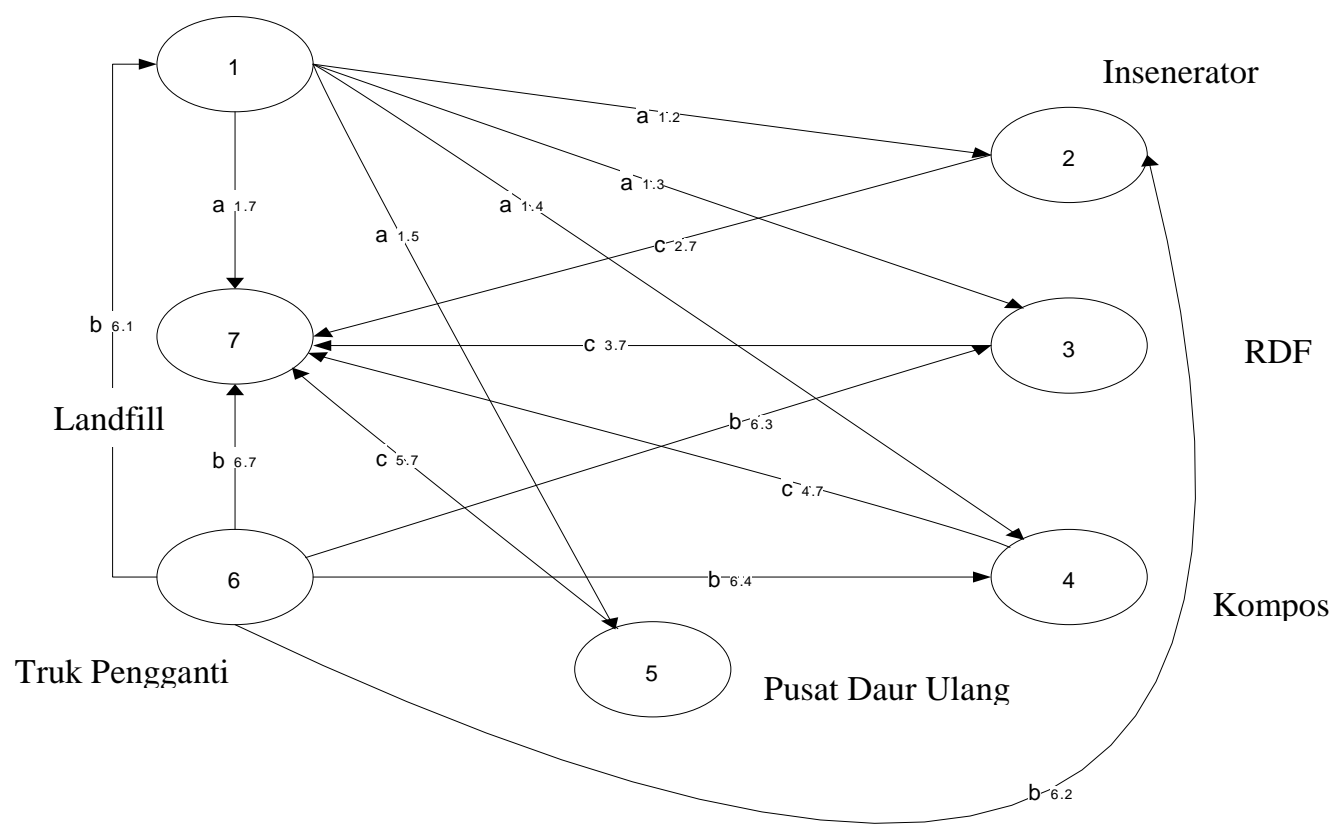

Gambar 1 : Alternatif Pengelolaan Sampah Kota Palu

\subsubsection{Menentukan Fungsi Biaya Pengelolaan Sampah}

Pengelolaan sampah diinginkan untuk menghasilkan biaya operasional yang minimum yang terdiri total atas biaya pengangkutan sampah dari sumber sampah ke insenerator,RDF, pengomposan, Daur ulang dan landfill dan total biaya pengangkutan sampah dari insenerator ke landfill, RDF ke landfill, pengomposan ke landfill dan daur ulang ke landfill. Biaya operasional lain adalah adalah biaya produksi di insenerator, RDF, Pengomposan, daur ulang dan biaya operasional landfill. Biaya lain yang harus dikeluarkan adalah biaya investasi pembelian truk.

Fungsi Biaya :

$\mathrm{F}_{1}$ : Total biaya operasional

$\mathrm{F}_{2}$ : Total biaya investasi

Dimana :

$$
\begin{aligned}
\mathrm{F}_{1}= & \left(\boldsymbol{a}_{12} \times \mu \times \alpha_{12} \times x_{12}\right)+\left(\boldsymbol{a}_{13} \times \mu \times \alpha_{13} \times x_{13}\right)+\left(\boldsymbol{a}_{14} \times \mu \times \alpha_{14} \times x_{14}\right)+ \\
& \left(\boldsymbol{a}_{15} \times \mu \times \alpha_{15} \times x_{15}\right)+\left(\boldsymbol{a}_{17} \times \mu \times \alpha_{17} \times x_{17}\right)+\left(\boldsymbol{b}_{27} \times \mu \times \beta_{27} \times y_{27}\right)+ \\
& \left(\boldsymbol{b}_{37} \times \mu \times \beta_{37} \times \boldsymbol{y}_{37}\right)+\left(\boldsymbol{b}_{47} \times \mu \times \beta_{47} \times \boldsymbol{y}_{47}\right)+\left(\boldsymbol{b}_{57} \times \mu \times \beta_{57} \times y_{57}\right)+
\end{aligned}
$$




$$
\begin{aligned}
& \left(z_{2} \times \mu \times \alpha_{12} \times x_{12}\right)+\left(z_{3} \times \mu \times \alpha_{13} \times x_{13}\right)+\left(z_{4} \times \mu \times \alpha_{14} \times x_{14}\right)+ \\
& \left(z_{5} \times \mu \times \alpha_{15} \times x_{15}\right)+\left(z_{7} t_{7}\right) \\
\mathrm{F}_{2}= & e(T+R T)
\end{aligned}
$$

Dengan $T$ : Banyaknya truk yang digunakan diman $T=x_{12}+x_{13}+x_{14}+x_{15}+x_{17}+$

$$
\boldsymbol{y}_{27}+\boldsymbol{y}_{37}+\boldsymbol{y}_{47}+\boldsymbol{y}_{57}
$$

RT : Banyaknya truk pengganti yang dibutuhkan dimana RT $=\boldsymbol{n}_{61}+\boldsymbol{n}_{62}+\boldsymbol{n}_{63}+$

$$
\boldsymbol{n}_{64}+\boldsymbol{n}_{65}+\boldsymbol{n}_{67}
$$

Selain fungsi biaya didefinisikan fungsi pendapatan yang diperoleh dari penjualan produk pengelolaan sampah sebagai berikut :

$$
B \text { : Pendapatan dari penjualan produk }
$$

Dimana :

$$
\begin{aligned}
& B=\left(d_{2}(1-\rho) \times \mu \times \alpha_{12} \times x_{12}\right)+\left(d_{3}(1-\rho) \times \mu \times \alpha_{13} \times x_{13}\right)+\left(d_{4}(1-\rho) \times \mu \times \alpha_{14} \times x\right. \\
& 14)+ \\
& \left(d_{5}(1-\rho) \times \mu \times \alpha_{15} \times x_{15}\right)
\end{aligned}
$$

Melalui pendefinisian tersebut masalah pengelolaan sampah dapat didefinisikan dengan model matematika sebagai berikut :

Meminimumkan Fungsi $\mathrm{F}_{1}+\mathrm{F}_{2}-B$.

Dengan kendala :

1. $\mu \times \alpha_{12} \times x_{12}+\mu \times \alpha_{13} \times x_{13}+\mu \times \alpha_{14} \times x_{14}+\mu \times \alpha_{15} \times x_{15}++\mu \times \alpha_{17} \times x_{17} \geq$ 600

2. $\rho_{2} \times \mu \times \alpha_{12} \times x_{12}$

$\leq \mu \times \beta_{27} \times y_{27}$

3. $\rho_{3} \times \mu \times \alpha_{13} \times x_{13}$

$\leq \mu \times \beta_{37} \times y_{37}$

4. $\rho_{4} \times \mu \times \alpha_{14} \times x_{14}$

$\leq \mu \times \beta_{47} \times y_{47}$

5. $\rho_{5} \times \mu \times \alpha_{15} \times x_{15}$

$\leq \mu \times \beta_{57} \times y_{57}$

6. $\boldsymbol{n}_{61}+\boldsymbol{n}_{62}+\boldsymbol{n}_{63}+\boldsymbol{n}_{64}+\boldsymbol{n}_{65}+\boldsymbol{n}_{67} \geq 0,13 \times \mathrm{T}$

7. $\mu \times \alpha_{12} \times x_{12}$

$\leq 1000,25$

8. $\mu \times \alpha_{13} \times x_{13}$

$\leq 1000$

9. $\mu \times \alpha_{14} \times x_{14}$

$\leq 1000,25$

10.

$\mu \times \alpha_{15} \times x_{15}$

$\leq 1000$

11. $\mathrm{t}_{7}$

$\leq 2000$

$\mathrm{t}_{7}$ : Banyaknya sampah di landfill, dimana $\mathrm{t}_{7}=\left(\mu \times \alpha_{17} \times x_{17}\right)+\left(\mu \times \beta_{27} \times y_{27}\right)+$

$$
\begin{array}{ll}
\left(\mu \times \beta_{37} \times y_{37}\right)+\left(\mu \times \beta_{47} \times y_{47}\right)+\left(\mu \times \beta_{57} \times y_{57}\right) & \text { (18) Dan variabel kondisi : } \\
x_{12}, x_{13}, x_{14}, x_{15}, x_{16}, x_{17}, y_{27}, y_{37}, y_{47}, y_{57} \geq 0 & \geq 0 \\
n 61, n 62, n 63, n 64, n 65 n 67 &
\end{array}
$$

Dalam menentukan biaya pengelolaan sampah jenis truk yang dipakai untuk mengangkut sumber sampah dikelompokkan pula atas jenis sampah yang memiliki jenis sama diangkut oleh truk yang sama. Sehingga banyaknya sampah yang diangkut dari sumber 
sampah di 1 ke pengelolaan sampah dengan jenis sampah yang serupa adalah sama, akibatnya :

1. Banyaknya sampah yang diangkut dari sumber sampah di 1 ke incenerator dan daur ulang di anggap sama.

2. Banyaknya sampah yang diangkut dari sumber sampah di $1 \mathrm{RDF}$ dan pengomposan di anggap sama

\subsubsection{Biaya Pengelolaan Sampah}

Bila diinginkan tidak ada sampah yang diangkut langsung dari sumber sampah ke RDF, dan pengomposan, maka solusi masalah pengelolaan sampah diperoleh dari fugsi kendala 1 dengan mengambil bilangan bulat terkecil yang memenuhi sebagai berikut :

$x_{12}=x_{14}=(400 /(6 x 5))=13$

$x_{17}=(200 /(6 x 5))=7$

Nilai $x_{12}$ dan yang diperoleh digunakan untuk menentukan $y_{27}$ dari fungsi kendala 2 dan diperoleh $\left.y_{27}, y_{47}=((0,7 \times 5) / 3)\right)=1$

Kemudian dari fungsi kendala 6 dengan $R T=3$. Maka diperoleh solusi $x_{12}=x_{14}=13, x_{13}=0$, $x_{15}=0, x_{17}=7$ dan $y_{27}=y_{47}=1$ dengan total biaya $F_{1}+F_{2}-B$ sebagai berikut :

$F_{1}=(0,50 \times 2 \times 6 \times 5 \times 13)+(0,50 \times 6 \times 5 \times 7)+(0,3 \times 2 \times 3 \times 1)+(0,7 \times 2 \times 6 \times 5 \times 13)+(0,7 \times$ 246)

$=1215$

$F_{2}=35000(21+3)=840.000$

$B=(392 \times 6 \times 5 \times 13)+(196 \times 6 \times 5 \times 13)=229.320$

Sehingga biaya yang dikeluarkan adalah $R p .6$. 110. 895. 000

Solusi optimal telah didapat dengan jumlah truk yang dgunakan adalah 21 sehingga pengangkutan sampahnya menjadi maksimal dengan biaya yang minimum. Dari solusi tersebut mencatat bahwa truk yang digunakan untuk memindahkan sampah dari sumber sampah ke insenerator dan daur ulang adalah 13, dan tidak lebih dari 1 truk digunakan untuk membawa sampah dari insinerator dan daur ulang ke landfill. Dari total biaya yang diperoleh dapat dilihat bahwa solusi tersebut baru melibatkan 2 produk pengelola sampah yaitu incinerator dan daur ulang. Untuk itu kita perlu mempertimbangkan kembali kombinasi truknya agar 2 produk sampah lainnya (yaitu RDF dan kompos) dapat dilibatkan sehingga biayanya dapat ditekan lagi. 


\subsubsection{Meninjau Kombinasi Banyaknya Truk Pengangkut Sampah}

Kita dapat mempertimbangkan kembali kombinasi truk yang digunakan untuk mengangkut sampah dari sumber ke RDF dan pengomposan agar sebagai berikut :

(i) Jika tujuh truk di gunakan untuk mengangkut sampah dari sumber ke insenerator dan daur ulang, satu truk digunakan untuk mengangkut sampah dari insenerator dan daur ulang ke landfill, dan empat truk digunakan mengangkut sampah dari sumber sampah ke landfill. Maka sampah yang terangkut dari sumber ke insenerator dan daur ulang adalah $6 \times 5 \times 7=210$ kubik dan sampah yang terangkut dari sumber ke landfill adalah $6 \times 5 \times 4=120$ kubik. Dengan demikian banyaknya sampah yang tidak terangkut dari sumber ke RDF dan pengomposan adalah 600-(210+120)=270 kubik. Sampah tersebut diangkut dengan $270 /(6 \times 5)=9$ truk. Sehingga total biaya sebesar $F_{1}+F_{2}-B$ :

$F_{1}=(0,5 \times 0,2 \times 6 \times 5 \times 7)+(0,5 \times 6 \times 5 \times 4)+(0,5 \times 0,2 \times 6 \times 5 \times 9)+(0,3 \times 4 \times 6 \times 3 \times$ 1) +

$(0,7 \times 2 \times 6 \times 5 \times 7)+(0,7 \times 2 \times 6 \times 5 \times 9)+(0,7 \times 240)=1158.6$

$F_{2}=35000(21+3)=840.000$

$B=(392 \times 6 \times 5 \times 7)+(196 \times 6 \times 5 \times 7)+(367 \times 6 \times 5 \times 9)+(140 \times 6 \times 5 \times 9)=260.370$

Sehingga Biaya yang dikeluarkan adalah $R p$. 5. 800. 788. 000. Hasil tersebut memperlihatkan bahwa biaya yang digunakan dapat ditekan. Hal ini disebabkan oleh meningkatnya pendapatan dari penjualan produk pengolahan sampah.

Jika lima truk di gunakan untuk mengangkut sampah dari sumber ke insenerator dan daur ulang satu truk digunakan untuk mengangkut sampah dari insenerator dan daur ulang ke landfill, dan lima truk digunakan dari sumber sampah ke landfill, maka sampah yang terangkut dari sumber ke insenerator dan daur ulang adalah $6 \times 5 \times 5=150$ kubik dan dari sumber sampah ke landfill adalah $6 \times 5 \times 5=150$. Banyaknya sampah yang tidak terangkut dari sumber ke RDF dan pengomposan adalah 600-(150/+150) $=300$ kubik. Sampah tersebut diangkut dengan menggunakan $300 /(6 \times 5)=10$ truk. Sehingga total biaya sebesar $\mathrm{F}_{1}+\mathrm{F}_{2}-\mathrm{B}$ :

$\mathrm{F}_{1}=(0,5 \times 2 \times 6 \times 5 \times 5)+(0,5 \times 6 \times 5 \times 5)+(0,5 \times 2 \times 6 \times 5 \times 10)+(0,3 \times 4 \times 6 \times 3 \times 1)+$ $(0,7 \times 2 \times 6 \times 5 \times 5)+(0,7 \times 2 \times 6 \times 5 \times 10)+(0,7 \times 270)=1365.6$

$F_{2}=35000(21+3)=840.000$

$B=(392 \times 6 \times 5 \times 5)+(196 \times 6 \times 5 \times 5)+(367 \times 6 \times 5 \times 10)+(140 \times 6 \times 5 \times 10)=240.300$

Sehingga biaya yang dikeluarkan adalah $R p$. 6. 010. 560. 000. Hasil tersebut memperlihatkan biayanya naik dikarenakan pendapatannya menurun sehingga biaya pengelolaannya lebih besar dibanding dengan biaya yang digunakan komposisi (i).

ii. Jika enam truk di gunakan untuk mengangkut sampah dari sumber ke insenerator dan daur ulang, satu truk digunakan untuk mengangkut sampah dari insenerator dan 
daur ulang ke landfill, enam truk digunakan dari sumber sampah ke landfill, maka sampah yang terangkut dari sumber ke insenerator dan daur ulang adalah $6 \times 5 \times 6=180$ kubik dan dari sumber sampah ke landfill adalah $6 \times 5 \times 6=180$. Dengan demikian banyaknya sampah yang tidak terangkut dari sumber ke RDF dan pengomposan adalah $600-(180+180)=240$ kubik. Sampah tersebut diangkut dengan menggunakan $240 /(6 \times 5)=8$ truk. Sehingga total biaya sebesar $F_{1}+F_{2}-B$ :

$F_{1}=(0,5 \times 2 \times 6 \times 5 \times 6)+(0,5 \times 6 \times 5 \times 6)+(0,5 \times 2 \times 6 \times 5 \times 8)+(0,3 \times 4 \times 6 \times 3 \times 1)+$ $(0,7 \times 2 \times 6 \times 5 \times 6)+(0,7 \times 2 \times 6 \times 5 \times 8)+(0,7 \times 300)=1329.6$

$F_{2}=35000(21+3)=840.000$

$B=(392 \times 6 \times 5 \times 6)+(196 \times 6 \times 5 \times 6)+(367 \times 6 \times 5 \times 8)+(140 \times 6 \times 5 \times 8)=227.520$

Sehingga biaya yang dikeluarkan adalah Rp. 6. 131. 120. 000. Hasil tersebut memperlihatkan biaya pengeluarannya lebih naik dibandingkan (i) dan (ii) karena pendapatan dari hasil jual produk menurun.

Meninjau Peran Parameter Persentasi(\%) atau Fraksi Sampah Yang Tidak Tertangani. Pengelolaan sampah yang optimal dapat diperoleh dengan menjaga fraksi sampah yang tidak tertangani sekecil mungkin. Bila fraksi sampah yang tidak tertangani kecil maka diharapkan biaya pengelolaan sampah menjadi rendah. Hal ini disebabkan keuntungan meningkat sehingga dapat menekan biaya pegeluaran. Untuk melihat peran fraksi sampah yang tidak tertangani terhadap biaya pengelolaan sampah di kota Palu maka ditinjau kasus-kasus berikut : a. Fraksi sampah yang tidak tertangani $\rho=0$ Pangambilan $\rho=0$ mengakibatkan :

$B_{1}=\left(560(1-0) \times 6 \times 5 \times x_{12}\right)$

$B_{2}=(245(1-0) \times 6 \times 5 \times 14)$

Dengan $\mathrm{B}=B_{1}+B_{2}$

Fungsi kendala 2 dan 4 tidak dapat lagi digunakan pula sehingga dimiliki :

$0 \times 6 \times 5 \times x_{12} \leq 6 \times 3 \times y_{27}$

$0 \times 6 \times 5 \times x_{14} \leq 6 \times 3 \times y_{47}$

Pengambilan $\rho=0$ juga mengakibatkan tidak ada lagi sampah terangkut dari insenerator dan kompos ke landfill $y\left(27=0, y_{47}=0\right)$. Begitu juga $x_{13}=0, x_{15}=0$, . Dari fungsi kendala 1 di peroleh

$x_{12}+x_{14}=(400 / 6 \times 5)=13$ dan $x_{17}=(200 / 6 \times 5)=7$ Maka di peroleh $\mathrm{T}=20, \mathrm{RT}=3$

$F_{1}=(0,50 \times 2 \times 6 \times 5 \times 13)+(0,50 \times 6 \times 5 \times 7)+(0,7 \times 2 \times 6 \times 5 \times 13)+(0,7 \times 210)=1.188$

$F_{2}=35000(20+3)=805.000$

$B=(560 \times 6 \times 5 \times 13)+(245 \times 6 \times 5 \times 13)=313.950$

Sehingga biaya yang dikeluarkan adalah $R p$. 4. 920. 238. 000

Karena ada keuntungan pada insenerator dan landfill kemungkinan solusi telah optimal, dengan memeriksa kembali kombinasi truk $(T=20)$. Telah diketahui bahwa maksimum 
jumlah truk yang digunakan untuk mengangkut sampah dari sumber ke insenerator dan daur ulang adalah 13,dan dari sumber ke landfill adalah 7. $y_{27}=0 y_{37}=0, y_{47}=0, y_{57}$ $=0$ karena $\rho=0$.

i. Jika tujuh truk di gunakan untuk mengangkut sampah dari sumber ke insenerator dan daur ulang dan empat truk digunakan mengangkut sampah dari sumber sampah ke landfill, maka sampah yang terangkut dari sumber ke insenerator dan daur ulang adalah $6 \times 5 \times 7=210$ kubik. Sampah yang terangkut dari sumber ke landfill adalah $6 \times 5 \times 4=120$ kubik.

Maka banyak sampah yang tidak terangkut dari sumber ke RDF dan pengomposan adalah $600-(210+120)=270$ kubik. Sampah yang terangkut ke RDF dan pengomposan adalah

$6 \times 5 \times 9=270$ kubik menggunakan 9 truk. Sehingga total biaya sebesar $F_{1}+F_{2}-B$ :

$F_{1}=(0,5 \times 2 \times 6 \times 5 \times 7)+(0,5 \times 6 \times 5 \times 4)+(0,5 \times 2 \times 6 \times 5 \times 9)+(0,7 \times 2 \times 6 \times 5 \times 7)+$ $(0,7 \times 2 \times 6 \times 5 \times 9)+(0,7 \times 120)=1296$

$F_{2}=35000(20+3)=805.000$

$B=(560 \times 6 \times 5 \times 7)+(245 \times 6 \times 5 \times 7)+(525 \times 6 \times 5 \times 9)+(175 \times 6 \times 5 \times 9)=358.000$

Sehingga Biaya yang dikeluarkan adalah $R p$. 4. 448. 296. 000.

ii. Jika lima truk di gunakan untuk mengangkut sampah dari sumber ke insenerator dan daur ulang dan lima truk digunakan dari sumber sampah ke landfill, maka sampah yang terangkut dari sumber ke insenerator dan daur ulang adalah $6 \times 5 \times 5=150$ kubik.dari sumber sampah ke landfill adalah $6 \times 5 \times 5=150$. Banyaknya sampah yang tidak terangkut dari sumber ke RDF dan pengomposan adalah 600-(150/+150) = 300 kubik. Sampah tersebut diangkut dengan menggunakan $300 /(6 \times 5)=10$ truk. Sehingga total biaya sebesar $F_{1}+F_{2}-B$ :

$F_{1}=(0,5 \times 2 \times 6 \times 5 \times 5)+(0,5 \times 6 \times 5 \times 5)+(0,5 \times 2 \times 6 \times 5 \times 10)+(0,7 \times 2 \times 6 \times 5 \times 5)+$

$(0,7 \times 2 \times 6 \times 5 \times 10)+(0,7 \times 120)=1239$

$F_{2}=35000(20+3)=805.000$

$B=(560 \times 6 \times 5 \times 7)+(245 \times 6 \times 5 \times 7)+(525 \times 6 \times 5 \times 10)+(175 \times 6 \times 5 \times 10)=378.550$

Sehingga biaya yang dikeluarkan adalah $R p .4$. 270. 689. 000.

iii. Jika enam truk di gunakan untuk mengangkut sampah dari sumber ke insenerator dan daur ulang dan enam truk digunakan dari sumber sampah ke landfill, maka sampah yang terangkut dari sumber ke insenerator dan daur ulang adalah $6 \times 5 \times 6=180$ kubik.dari sumber sampah ke landfill adalah $6 \times 5 \times 6=180$. Dengan demikian banyaknya sampah yang tidak terangkut dari sumber ke RDF dan pengomposan adalah $600-(180+180)=$ 240 kubik. Sampah tersebut diangkut dengan menggunakan $240 /(6 \times 5)=8$ truk . Sehingga total biaya sebesar $\mathrm{F}_{1}+\mathrm{F}_{2}-\mathrm{B}$ :

$F_{1}=(0,5 \times 2 \times 6 \times 5 \times 6)+(0,5 \times 6 \times 5 \times 6)+(0,5 \times 2 \times 6 \times 5 \times 8)++(0,7 \times 2 \times 6 \times$

$5 \times 6)+(0,7 \times 2 \times 6 \times 5 \times 8)+(0,7 \times 300)=1308$ 
$F_{2}=35000(210+3)=805.000$

$B=(546 \times 6 \times 5 \times 6)+(238,875 \times 6 \times 5 \times 6)+(367 \times 6 \times 5 \times 8)+(140 \times 6 \times 5 \times 8)=$ 227.520 Sehingga biaya yang dikeluarkan adalah $R \boldsymbol{p}$. 5. 780. 788. 000.

Tabel 4 : Pengelolaan Sampah Kota Palu

\begin{tabular}{|c|c|c|c|c|c|}
\hline & Konvensional & \multicolumn{4}{|c|}{ Modern } \\
\hline \multirow{3}{*}{ Biaya } & \multirow{3}{*}{$\begin{array}{c}\text { Rp. } \\
8.050 .330 .000\end{array}$} & \multirow[b]{2}{*}{2 Produk } & \multicolumn{3}{|c|}{4 produk } \\
\hline & & & $\begin{array}{l}\text { Kombinasi } \\
\text { truk } \\
\text { (i) }\end{array}$ & $\begin{array}{c}\text { Kombinasi } \\
\text { truk } \\
\text { (ii) }\end{array}$ & $\begin{array}{c}\text { Kombinasi } \\
\text { truk } \\
\text { (iii) }\end{array}$ \\
\hline & & $\begin{array}{c}\text { Rp. } \\
6.110 .895 .000\end{array}$ & $\begin{array}{c}\text { Rp. } 5.800 .788 \\
.000\end{array}$ & $\begin{array}{c}\text { Rp.6.010.5 } \\
60.000\end{array}$ & $\begin{array}{c}\text { Rp. } 6.131 .120 \\
.000\end{array}$ \\
\hline
\end{tabular}

\section{KESIMPULAN}

1. Alternatif pengelolaan sampah modern dikelola dengan mengubah sampah menjadi produk yang punya nilai jual, sehingga dapat menekan biaya pengeluaran karena terdapat pendapatan dari penjualan produk menjadi Rp. 5.800.788.000. Biaya pengelolaan sampah modern dapat ditekan dengan meminimumkan banyaknya sampah dari sumber yang langsung diangkut ke landfill agar mencegah fungsi pendapatan akan mengecil, sehingga biaya yang dikeluarkan akan semakin besar.

2. Pengkajian terhadap $\rho$ (fraksi sampah yang tidak tertangani) memperlihatkan bahwa semakin besar $\rho$ maka biaya pengelolaan sampah menjadi semakin besar karena pendapatan dari penjualan produk akan semakin menurun .

\section{DAFTAR PUSTAKA}

[1] Arianto Wibowo \& Darwin T Djajawinata, Penanganan Sampah Perkotaan Terpadu, Kumpulan Makalah, Bappenas, 2003.

[2] Dinas Kebersihan Kota, Profil Dinas Kebersihan Kota Palu Pemerintah Kota Palu. Sulawesi Tengah, 2004.

[3] Hadiwiyoto, Soewedo. 1983. Penanganan dan Pemanfaatan Sampah. Jakarta :Mediyatama Sarana Perkasa.

[4] Mukono HJ. (1999). Pinsip-Prinsip Dasar Kesehatan Lingkungan .Surabaya: Airlangga University Press.

[5] Suprapto. J. M. A., 1983, Linear Programming. Jakarta: Fakultas Ekonomi Universitas Indonesia.

[6] Siringoringo. (2005). Metode Simpleks. (http://elearning.unram.ac.id/riset/pdf- 
doc/modul/Dokumen/Simplex.pdf). Diakses 13 Januari 2012.

[7] Susanta. B. 1994, Program Linier. Seri buku ajar.

[8] Taha Hamdi A. 1996. Riset Operasi. Binarupa Aksara. Jakarta Barat.

[9] Wikipidia, Pengelolaan Sampah,http://id.wikipedia.org/wiki/Pengelolaan_samp-ah.Diakses 20 Februari 2012 .

[10] Yani, M. dan A. A. Darwis. 1990. Diktat Teknologi Biogas. Pusat Antar Universitas Bioteknologi - IPB. Bogor. 